\title{
Nuclear cardiology in the UK 1994: activity relative to Europe, USA, and British Cardiac Society targets
}

\author{
D J Pennell, E Prvulovich, A Tweddel, J Caplin
}

Magnetic Resonance Unit, Royal Brompton Hospital, London, UK D J Pennell

\section{Department of Nuclear Medicine, University College London Medical School, London, UK \\ E Prvulovich}

Department of

Nuclear Cardiology, University Hospital of Wales, Cardiff, UK A Tweddel

Department of Cardiology, Hull Royal Infirmary, Hull, UK

J Caplin

This paper was published in full-Pennell DJ, Prvulovich $\mathrm{E}$, Tweddel A, et al. Nucl Med Commun 1998;19:305-13to which the reader is referred for fuller details of the survey. Publication of this brief article with the most salient points for cardiologists is with the permission of Heart (BMJ Publishing Group) and Nuclear Medicine

Communications (Thomson Science and Professional).

Correspondence to: Dr D J Pennell, Director Clinical MRI, Royal Brompton Hospital Sydney Street, London SW3 6NP, UK

email:d.pennell@ic.ac.uk

\begin{abstract}
Objective-To survey practice in nuclear cardiology in the UK in 1994.

Design-A questionnaire was sent to 219 centres performing nuclear imaging asking for details of current practice in nuclear cardiology. Replies were received from 192 centres $(88 \%)$.

Main outcome measures-Activity in performance of myocardial perfusion imaging (MPI) and radionuclide ventriculography (RNV), anticipated changes in activity, differences between regional and district hospitals, technical imaging parameters, and referral sources.

Results-Of the responding centres, 125 (65\%) performed nuclear cardiology procedures. More regional than district hospitals performed nuclear cardiology procedures $(85 \% v 55 \%, p<0.0003)$ and regional centres performed a higher proportion $(62 \% v 24 \%$, p < 0.001$)$ of nuclear cardiology activity. Nuclear cardiology activity was 0.82 scans per 1000 population per year (MPI 0.56, RNV 0.26). There has been a significant increase (24\%) in nuclear cardiology since 1988 . There has been a pronounced rise in MPI (350\%) while RNV has fallen by $47 \%$. Myocardial perfusion activity in the UK remains very low $(25 \%$ and $5 \%$ in regional and district hospitals, respectively) compared with the 1994 figures of 2.2/1000/year for Europe or $10.8 / 1000 / y e a r$ for the USA.

Conclusions-MPI has increased on average by $23 \%$ /annum (compound rate) since 1988 , but in 1994 was still only $32 \%$ of the British Cardiac Society target of 2.6/1000/ year. Proper resources for capital expenditure on new equipment and new staff will be important to maintain momentum in closing the gap. Also important is improved clinical understanding, as already implemented by including nuclear cardiology in guidelines for specialist cardiology training.

(Heart 1998;80:296-298)
\end{abstract}

Keywords: survey; nuclear cardiology; myocardial perfusion imaging; radionuclide ventriculography; guidelines; British Cardiac Society

Nuclear cardiology is an important investigation for cardiovascular disease in the USA and much of mainland Europe. ${ }^{12}$ Previous surveys of nuclear cardiology suggest that utilisation of these techniques is lagging behind in the UK. ${ }^{3}$
This survey was conducted to ascertain the trends and changes in nuclear cardiology practice since $1988 .^{3-6}$ In 1994, a survey was mailed to 219 nuclear medicine centres in the UK identified from radiopharmaceutical supply lists. A useful response was obtained from 192 centres $(88 \%)$. These were categorised into district hospitals $(n=130)$, regional hospitals $(\mathrm{n}=54)$, and private/military hospitals $(\mathrm{n}=8)$.

\section{Results}

ACTIVITY

Overall, 125 centres in the UK ( $65 \%$ of centres responding) were performing nuclear cardiology procedures. Practice was more frequent in regional than in district hospitals $(85 \% v 55 \%$, $\mathrm{p}<0.0003$ ), and regional hospital activity represented a significantly higher proportion of total nuclear medicine workload $(12 \% \vee 5 \%$, $\mathrm{p}<0.001)$. The total number of nuclear cardiology procedures in all centres was 39929 ( $8.9 \%$ of total nuclear medicine workload). Assuming an equal proportion of workload among the non-responders to the survey, these figures suggest an annual total of 45500 nuclear cardiology tests $(0.82$ scans per 1000 population per year).

For myocardial perfusion imaging (MPI), 27445 procedures were reported $(69 \%$ of total), and for radionuclide ventriculography (RNV), 12484 (31\%), of which 90\% were performed at rest only. The adjusted total UK figures for these studies were 31300 for MPI (0.56/1000/year) and 14200 for RNV (0.26/ $1000 /$ year). Each centre quoted their current trend for nuclear cardiology workload, and 71 replied that it was increasing, 31 static, and 10 indicated a view towards reducing. Ten district hospitals stated their intention to begin nuclear cardiology procedures in the near future.

\section{Discussion}

NUCLEAR CARDIOLOGY GROWTH

There has been considerable recent increase in the role of nuclear cardiology in the routine management of patients with cardiovascular diseases. This has been spearheaded in the USA where extensive training courses for cardiology fellows and large numbers of clinical validation studies have led to complete acceptance of the value of the techniques. While interest has been building in the UK, there has been a lag period, and there is no doubt that activity is a long way behind that of the USA and mainland Europe. 


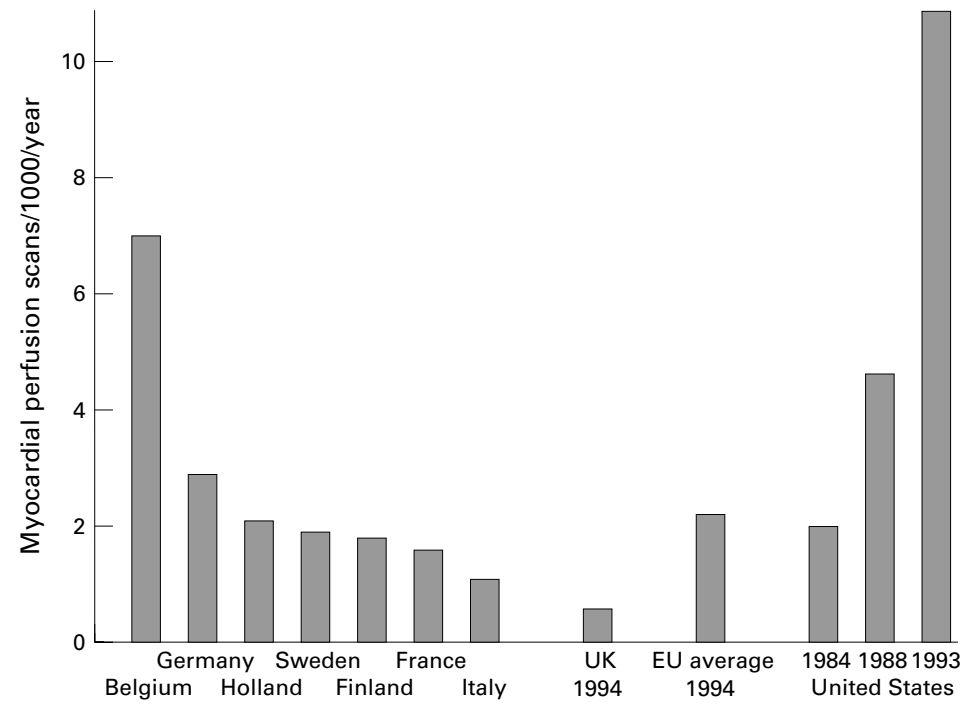

Figure 1 Comparison of the activity per head of population for MPI in developed European countries and the USA. The UK has the lowest activity at approximately one third the European average.

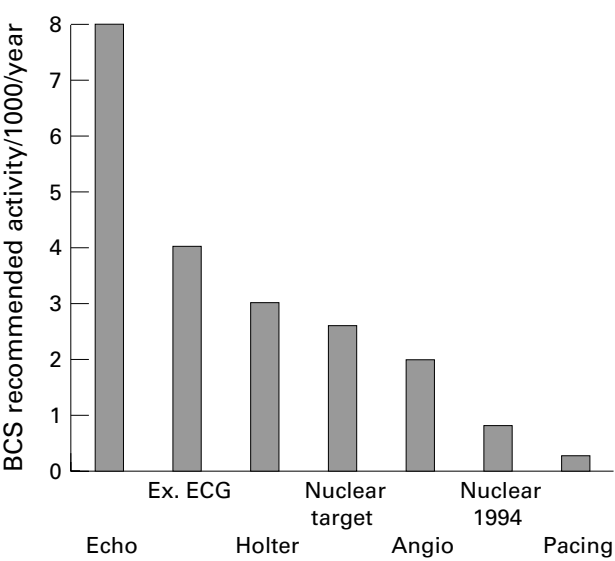

Figure 2 British Cardiac Society recommendations for activity in cardiology procedures and the activity in 1994.

status (fig 1). This situation is exacerbated by our high standardised mortality rates for coronary artery disease, which suggest that our rate for cardiovascular investigations should be higher than other countries. This has been recognised by the British Cardiac Society, ${ }^{13}$ and a target of raising our levels of nuclear cardiology activity (MPI 2.2/1000/ year plus RNV 0.4/1000/year) towards European levels (total 2.6/1000/year in 1994) has been made in recent recommendations (fig 2). ${ }^{14}$ Thus for a district hospital with a catchment area of 250000 people, a target of 550 myocardial perfusion scans per year (about 10 each week) would be appropriate. Specialist centres might wish to aim for up to three times average, perhaps 1500 patients per year (about 30 each week). From this survey, only $11(22 \%)$ regional and one $(1 \%)$ district general hospital met the target activity.

Clearly, an expansion of nuclear cardiology services has resource implications particularly for staff and capital expenditure required for the provision of modern tomographic scanners. For many centres, replacement or additional cameras are necessary if the target activity is to be realised. The cost of such equipment is similar to that of a top of the range echocardiography machine. At least progress has been made in the improvement of clinical understanding of the techniques with the publication of the training requirements for specialist registrars in cardiology in the UK, which now includes a compulsory period of training in nuclear cardiology, ${ }^{15}$ something that remains sadly missing from undergraduate curricula.

\section{The future}

The crude annual estimate for the compound market growth since 1988 in myocardial perfusion imaging is $23 \%$ per annum. This figure accords with latest estimates for MPI in 1995, which is 38000 (0.69/1000/year). European activity is rising at approximately $9 \%$ per year, which is lower than that in the UK, but overall activity is much higher than in the UK (in 1994, 2.2/1000/year). Thus, although we were performing only a quarter of European activity in 1994, we may have started to catch up. Comparisons with Europe and the USA, ${ }^{12}$ show the UK at the lower end of activity for MPI among countries of similar economic
1 Zaret BL, Wackers FJ. Nuclear cardiology. Review article I. N Engl fै Med 1993;329:775-83.

2 Zaret BL, Wackers FJ. Nuclear cardiology. Review article II. N Engl f Med 1993;329:855-63.

3 Underwood SR, Gibson C, Tweddel A, et al, on behalf of the British Nuclear Cardiology Group. A survey of nuclear 273-7.

4 Wall BF, Hillier MC, Kendall GM. Nuclear medicine activity in the United Kingdom. Br F Radiol 1985;58:125-30. 90. Nucl Med Commun 1993;14:360-4.

6 Elliott AT, Elliott FM, Shields RA. UK nuclear medicine survey, 1992-93. Nucl Med Commun 1996;17:3-7.

7 Iskandrian AS, Chae SC, Heo J, et al. Independent and emission computed tomography (SPECT) thallium imagemission computed tomography (SPECT) thallium imag-
ing in coronary artery disease. $\mathcal{F}$ Am Coll Cardiol
1993;22:665-70. cardiological practice in Great Britain. Br Heart fु 1992;67:

5 Elliott AT, Shields RA. UK nuclear medicine survey, 1989/ incremental prognostic value of exercise single photon 
8 Lauer MS, Lytle B, Pashkow F, et al. Prediction of death and myocardial infarction by screening with exercise thallium testing after coronary artery bypass grafting. Lancet 1998:351:615-22.

9 Pennell DJ, Mavrogeni S, Forbat SM, et al. Adenosine combined with dynamic exercise for myocardial perfusion imaging. 7 Am Coll Cardiol 1995;25:1300-9.

10 Udelson JE, Coleman PS, Metherall J, et al. Predicting recovery of severe regional ventricular dysfunction. Comparison of resting scintigraphy with ${ }^{201} \mathrm{Tl}$ and ${ }^{99 \mathrm{~m}} \mathrm{Tc}-$ sestamibi. Circulation 1994;89:2552-61.

11 Pennell DJ, Prvulovich E. Nuclear cardiology. London: British Nuclear Medicine Society, 1995.
12 Giering LP, Smith JE. Industrial perspective: from IND to NDA. F Nucl Cardiol 1995;2:66-70.

13 A report of a working group of the British Cardiac Society: cardiology in the district general hospital. Br Heart F 1994; 72:303-8.

14 Council statement on the demand and need for cardiac services and the development of a waiting list strategy for cardiac disease. London: British Cardiac Society, 1994.

15 British Cardiac Society and Specialist Advisory Committee in Cardiovascular Medicine of the Royal College of Physicians. Guidelines for specialist training in cardiology. $\mathrm{Br}$ Heart f 1995;73(suppl 1):1-24.

\section{A calcified occlusion of the left main coronary artery in a young man}
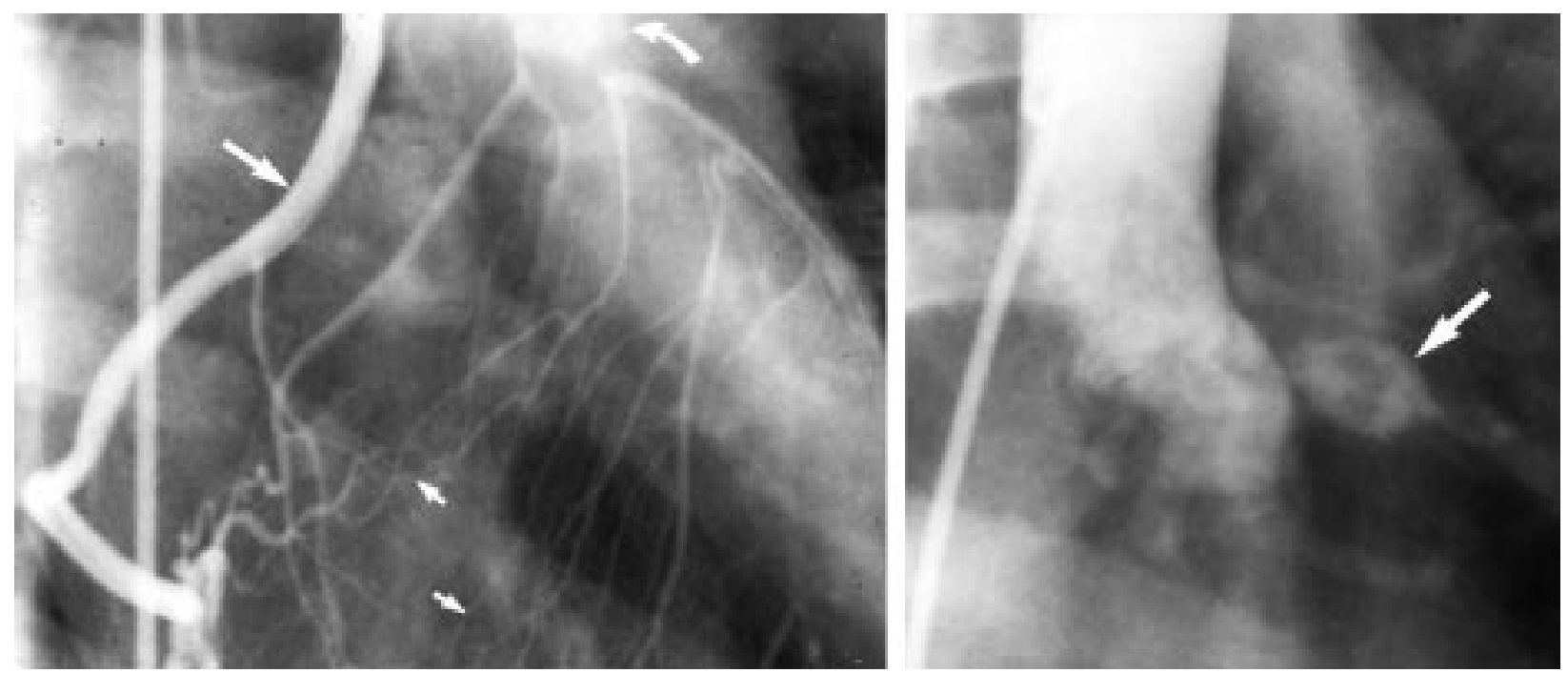

A 19 year old man was successfully resuscitated from ventricular fibrillation that occurred during exercise. Stress testing induced severe global ischaemia of the left ventricle. Coronary angiography (left) showed a normal right coronary artery (long arrow) that perfused the left coronary artery through peripheral collaterals (short arrows). At the site of the left main coronary artery, a dense radio-opaque mass was seen (curved arrow). On aortography, no antegrade flow of contrast through the mass into the left coronary artery could be seen (right, mass indicated by arrow). At the age of 2 years the patient had been hospitalised for 6 months because of a severe febrile illness with a generalised rash, for which no diagnosis was established at the time. The findings on angiography combined with this history suggest Kawasaki disease. The left internal mammary artery was grafted to the left anterior descending artery, and the patient made a full recovery.

R J G PETERS C E SCHOTBORGH J A P VAN DER SLOOT 